\title{
An empirical test of the rent-shifting hypothesis: the case of state trading enterprises
}

\author{
Stephen F. Hamilton ${ }^{\mathrm{a}}$, Kyle W. Stiegert ${ }^{\mathrm{b}}$ \\ ${ }^{a}$ Department of Economics, University of Central Florida, Orlando, FL 32816-1400, USA \\ ${ }^{\mathrm{b}}$ Department of Agricultural and Applied Economics, University of Wisconsin-Madison, Madison,
} WI, USA

\begin{abstract}
A central result in the theoretical literature on strategic trade is the 'rent-shifting hypothesis', the idea that government's can employ trade policy as a precommitment device to transfer profit from foreign to domestic firms. To our knowledge, however, the rent-shifting hypothesis remains untested empirically. This paper constructs a theory-based empirical test of rent-shifting behavior that relies on observations of government precommitment variables employed through State Trading Enterprises (STEs). The analysis applies data on the delayed producer payment structure of the Canadian Wheat Board (CWB) and examines its merits as a rent-shifting mechanism in the international durum market. The model fails to reject the hypothesis that the CWB utilizes a pre-commitment mechanism in the international durum market and several nonparametric tests confirm that the observed transfer payments set by the CWB are consistent with rent-shifting behavior in the 1972-95 pre-WTO period.
\end{abstract}

Keywords: Profit shifting; Vertical separation; New empirical industrial organization 


\section{Introduction}

Beginning with the seminal work of Brander and Spencer (1984, 1985), a large and growing literature has addressed what has become known as the 'rent-shifting hypothesis', the possibility that government trade policy can be used as a device to transfer profits from foreign to domestic firms. The theoretical foundation for strategic trade policy has subsequently developed in several important directions. Brander and Spencer (1988), Spencer and Jones (1991, 1992), Fung (1995), Ishikawa and Lee (1997), and Ishikawa and Spencer (1999)), among others, consider the effect of vertical structure on strategic trade and characterize how various incentive schemes and patterns of intermediate goods exchange bear on the optimal rent-shifting policy design. Neary (1994) examines the relationship between the social cost of public funds, transnational differences in production costs, and the optimal level of a domestic export subsidy. Dixit (1988) and Qiu (1995) consider circumstances under which countervailing duties by an importer provide sufficient deterrence to curtail the rent-shifting activities of an exporting country. Goldberg (1995) and Karp and Perloff (1995) investigate the strategic trade implications of limited government commitment, and Bagwell and Staiger (1994), Maggi (1996) and Brainard and Martimort (1998) examine the effect of incomplete information on the optimal rent-shifting mechanism. In light of the considerable theoretical attention devoted to strategic trade policy, it is somewhat surprising to note that the rent-shifting hypothesis remains untested empirically. The goal of the present paper is to provide this link.

The theoretical underpinnings of our approach are as follows. According to the rent-shifting hypothesis (in any of its various forms), a mechanism must exist for a government to establish some form of precommitment in the export market. Through precommitment to a particular trade policy, the government can then use an appropriately designed mechanism to shift rent from foreign to domestic firms by effectively lowering the marginal cost of domestic production (e.g., with a unit subsidy). In quantity-setting games, the relative unit cost differential between domestic and foreign firms derived through such a policy leads to a commensurate output differential that, in an optimally designed precommitment program, is exactly that which would occur in a Stackelberg leader-follower relationship

\footnotetext{
${ }^{1}$ Several papers have estimated mark-ups of price over marginal cost in international markets (see, e.g., Aw (1992), Levinsohn (1993), Harrison (1994), and Goldberg and Knetter (1999)). However, these papers address the degree of international market competition, and not the related questions we examine here, which are: (i) is there evidence of pre-commitment in the international data, and (ii) given an estimated level of structural competitiveness of the international market, is the relevant pre-commitment parameter set at the optimal level to shift-rent?

${ }^{2}$ In quantity-setting games, this mechanism is typically an output (or investment) subsidy, although the treatment extends readily to various other trade instruments, such as tariffs and import quotas.
} 
between domestic and foreign industry groups. The empirical challenge to an examination of the rent-shifting hypothesis is that the analysis must make a corresponding conceptual division; the prescription of precommitment precludes market data from being viewed as the outcome of a single-stage game. Consequently, we divide our empirical analysis into two sections that correspond to each of the two stages considered in the theory: a precommitment stage, in which a government chooses the optimal rent-shifting transfer, and an output stage, in which foreign and domestic marketing agents respond.

Our empirical approach is developed through the use of two procedures, each of which conforms to an individual stage-game suggested by theory. In the first procedure, which corresponds to the output stage-game, demand and conduct parameters are estimated in a segmented international market comprised of two exporting regions and one importer. The domestic export region, the region hypothesized to shift rent, is represented by a nationally sanctioned marketing agent with exclusive control of all domestic output, whereas a group of foreign marketing agents conducts independent marketing activities in the remaining export region. We estimate the output stage in the tradition of existing models of asymmetric cost equilibria (see, e.g., Kahai et al. (1996) and Berg and Kim (1998)), with one notable difference: government trade policy is considered as a shift parameter in the domestic marginal cost function. In the second procedure, which corresponds to the precommitment stage of the theoretical model, we employ a subset of the output stage results to characterize the value of the trade policy parameter associated with the optimal degree of rent-shifting. Two nonparametric statistical approaches (a Wilcoxon signed-rank test and a bootstrap method) are subsequently utilized to evaluate the relationship between the estimated optimal and observed transfer payments made between the domestic government and its marketing agent.

The merits of this empirical approach are 2-fold. First, if the domestic government does in fact use a form of precommitment in the international market, then the observed trade policy parameter can be used to derive an initial test of the rent-shifting hypothesis in the output stage model. Namely, because the reaction of foreign marketing agents to a change in the quantity of domestic exports is endogenous in the precommitment stage, this implies that the conduct parameter associated with the domestic marketing agent, itself, is pre-determined. Indeed, it is precisely this implicit functional relationship that makes rent-shifting behavior possible. As we demonstrate in the empirical section of the paper, this determinacy leads to the following necessary condition for rent-shifting behavior. When the conduct of the domestic marketing agent(s) is estimated as a free parameter in the output stage, trade policy is an effective rent-shifting mechanism only if the conduct parameter is of unit value. The second merit to our approach is that the parameters estimated in the output stage also define the optimal level at which the government precommitment variable should be set. Correspondingly, if the necessary condition for rent-shifting behavior cannot be rejected in the output 
stage model, it is possible to calculate the optimal precommitment level and test whether the observed trade policy parameter is set in a fashion consistent with theory.

We choose to focus our empirical analysis on the delayed producer payment system of State Trading Enterprises (STEs). The behavior of STEs in international markets is well suited to our purpose in several regards. First, unlike the case of rent-shifting arrangements between a government agent and private firm(s), which may be complicated by, among other things, strategic delegation issues and asymmetric information problems, STEs operate through a single marketing board with the exclusive control of both the instrument for strategic trade (i.e., the unit transfer price) and the quantity traded. Second, time-series data on STE activities are publicly available. Finally, apart from reasons of purely analytical convenience, the behavior and practices of STEs are important in their own right. At least since the Uruguay settlement of GATT, the role and behavior of STEs, which have reported objectives that include protection of domestic markets from world market influence and expansion of export market shares, have been a major concern in the emerging international commitment to free trade (GAO, 1995).

We apply our test of the rent-shifting hypothesis to the international durum market. International durum trade is an analytically convenient subject to study, as durum wheat is a relatively homogeneous commodity with a limited number of global exporters. Over the pre-WTO period 1971-95 that comprises our data, moreover, the durum market is served by a single STE, the Canadian Wheat Board $(\mathrm{CWB})$. ${ }^{3}$ Our principle finding is that the delayed producer payment structure implemented by the CWB in this period is consistent with rent-shifting behavior. Further analysis of individual marketing years supplements this result, moreover, as the actual pre-payment discount implemented by the CWB and the estimated optimal rent-shifting transfer cannot be statistically differentiated in 17 of 24 sample years.

The remainder of the paper is structured as follows. Section 2 provides background information that summarizes the current pricing practice of the CWB, with particular attention directed towards the payment structure in the durum market. Section 3 presents a theoretical framework that outlines the essential details of how a delayed producer payment system serves as a rent-shifting device and derives the central estimation equations we pursue in the empirical portion of the paper. Section 4 outlines the empirical methodology. Section 5 contains the estimation results, and, in Section 6, the paper concludes with a brief summary of our findings and suggestions for future work.

\footnotetext{
${ }^{3}$ The CWB is authorized under Canadian law to have near complete autonomy over the marketing, storage, logistics, and pricing of the nation's hard wheat, durum and barley exports.
} 


\section{State trading enterprises, vertical separation, and precommitment}

In the Uruguay settlement of GATT, the current WTO member nations made significant commitments toward freer trade through tariffication of quotas, scheduled reductions in internal production and trade distortions, and tightened definitions of national autonomy in a new hard law framework. A major issue of concern in this settlement regarded STE activity. In particular, the question arose as to whether the programs instituted by STEs could be tailored to circumvent the growing international commitments toward free trade.

In the post-Uruguay period, the US Congress commissioned the General Accounting Office to conduct two studies investigating and interpreting STE behavior (GAO, 1995, 1996). In these studies, STEs were shown to use policy tools that have reasonably clear WTO compliance rules, including production and import levies, price supports, and export subsidies (GAO, 1996). The reports also cited several other STE activities that are more problematic under WTO law, including export licenses, subsidies not tied marginally to a commodity, access to below-market borrowing rates, tax advantages, transportation subsidies, and delayed producer payments.

The GAO (1996) study recognized delayed producer payments as a source of pricing flexibility, because STEs initially set producer payments before final export marketing conditions are revealed. However, the report failed to draw attention to another important feature of the delayed payment system: almost exclusively, the initial payments for commodities brokered by STEs are set at substantially below-market prices. The large body of literature on vertical separation suggests that similarly structured payment systems between upstream and downstream firms are capable of generating the necessary precommitment mechanism to attain a Stackelberg leadership position (see, e.g., Bonanno and Vickers (1988); Lin (1988); Coughlin and Wernerfelt (1989), and Kühn (1997)). By setting a belowmarket procurement price for a commodity, a legally sanctioned STE is thus able to shift rent in the export market in much the fashion that a downstream firm in a vertically structured industry can strategically position itself through use of an upstream price restraint. ${ }^{4}$ Moreover, in the case of STEs, the final payment in a delayed producer payment system, which is typically delivered in lump-sum fashion, provides an explicit method of transfer back to the input supplier that rationalizes the system.

The essence of the vertical separation argument, as it relates here, is as follows. Through an appropriately structured system that employs below-market pricing of

\footnotetext{
${ }^{4}$ See Hamilton and Stiegert (2000) for an analysis of the antitrust implications of such vertical arrangements in international markets.
} 
an upstream product with a linear combination of lump-sum payments and equity sharing arrangements with the input supplier, a downstream firm can attain the requisite precommitment for Stackelberg leadership. The delayed payment system in a STE is of precisely this form: the STE typically pays upstream producers a below-market price, then later provides lump-sum reimbursement after proceeds are generated in a downstream international market. Consequently, the delayed payment approach is capable of creating a credible marginal cost advantage for the STE in an international market, therein providing the necessary precommitment to shift rent. The delayed producer payment structure is equivalent in this regard to a policy of direct export subsidization.

In the particular example we pursue here, the delayed payment system of the CWB, Canadian durum producers are required to market all output through the CWB both for domestic consumption and for export. In each year, the initial payment is announced by the CWB prior to harvest. Fig. 1 highlights the details of this payment system for durum wheat. In the figure, the total height of each bar is the price received by Canadian producers in each year, which is the sum of initial, middle, and final payments provided by the CWB. The lower portion of each bar is

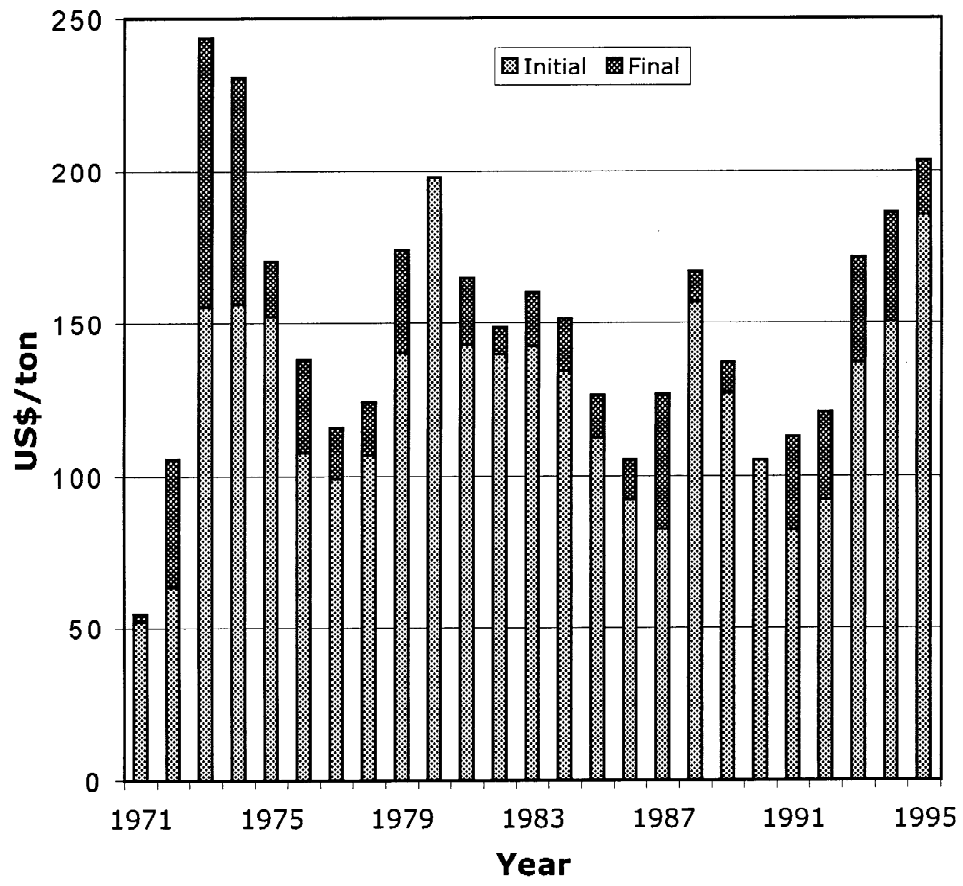

Fig. 1. CWB durum payments, 1971-1995. 
the initial payment paid to producers at the time they relinquish the grain, while the upper portion represents the sum of middle and final payments to producers after all revenue, net of cost, is determined.

The salient feature of Fig. 1 is that the CWB consistently delays payment for a substantial portion of the unit value of durum wheat. This deferred portion of the unit value represents a shift in cost between what is essentially a marginal cost and a fixed cost component of the CWB. For the reasons mentioned above, which we lay out more formally in the next section, we take the level of this pre-payment discount, the difference between the initial payment and the resulting world market price in each year, to represent the precommitment parameter through which a rent-shifting outcome obtains.

There are several circumstances of durum trade that are particularly well suited for a test of the rent-shifting hypothesis. First, the CWB is the major international player in the durum market. As the sole Canadian exporter for durum wheat, the CWB has maintained a 40-60\% export market share over the past several decades (International Wheat Council). Relative to the other commodities sold under its auspice, moreover, which include hard wheat and barley, the CWB channels a larger share of its durum to export markets: for example, in the 1988-1995 period, only $5-8 \%$ of the durum crop was sold domestically. Second, unlike the international hard wheat and barley markets, in which the Australian Wheat Board and Australian Barley Board operate their own delayed producer payment programs, the CWB does not compete with other STEs in the durum market. Finally, only limited substitution is possible for durum in its primary end-uses of semolina flour and pasta formulas. These elements of the durum market allow us to implement a relatively straightforward empirical approach.

\section{Theoretical structure}

This section provides a conceptual framework to identify the important features of the delayed producer payment system as a rent-shifting mechanism. Throughout, attention is confined to circumstances in which a single STE operates in the international market, which conforms with our empirical development of CWB behavior in the next section.

Consider a global export commodity that is produced in two production regions, a domestic region, in which operations are organized through a STE, and a foreign region composed of $n$ independent producers. Global production of the export commodity is structured in a vertical system comprised of an upstream input market in each country and a single downstream international market. For analytic simplicity, upstream firms produce the input at constant unit costs of $c_{\mathrm{D}}$ and $c_{\mathrm{F}}$ in the domestic and foreign country, respectively, and each downstream marketing 
agent serves as a pure intermediary in the production of the finished product. ${ }^{5} \mathrm{We}$ further assume that the domestic STE has exclusive control over all input purchases and has the authority to set the upstream market price in a procurement contract, the details of which are specified in some detail below. In the foreign region, downstream marketing agents are constrained to purchase the input on the spot market, as would be the case when legal restrictions prevent the explicit control of upstream market prices. For example, antitrust legislation in the US limits the ability of a marketing agent to set the input price through an upstream price restraint.

Strategic interaction between the marketing agents is modeled as a two-stage game. In the first stage, the precommitment stage, the STE selects an upstream transfer price, $w$, for the product. Participation by upstream producers in the market is mandatory at this price. In the second stage, the STE and the foreign marketing agents compete in quantities in an international oligopoly market. At the conclusion of this output stage, proceeds acquired by the STE through international durum sales are returned in a lump-sum fashion to the upstream producers.

Let $Q$ represent total output of the final good and denote the downstream inverse demand function as $P(Q)$, which is assumed throughout to be strictly decreasing and twice continuously differentiable. Downstream marketing costs are assumed to be linear in output and are henceforth subsumed into the market price. Finally, we impose the stability condition

$$
P^{\prime}(Q)+Q P^{\prime \prime}(Q)<0
$$

which, as demonstrated by Novshek (1985), ensures the existence of equilibrium.

The model is solved using backward induction. In the output stage, the STE seeks to

$$
\operatorname{Max}_{q_{\mathrm{D}}} \pi_{\mathrm{D}}\left(q_{\mathrm{D}}, Q, w\right)=(P(Q)-w) q_{\mathrm{D}}
$$

where $\pi_{\mathrm{D}}$ and $q_{\mathrm{D}}$ denote the level of profit and output for the STE in the export market, respectively, and $w$ is the transfer price set in the precommitment stage. Maximization of (2) with respect to $q_{\mathrm{D}}$ yields the first-order necessary condition:

$$
P(Q)+q_{\mathrm{D}} P^{\prime}(Q)-w=0
$$

Next, let $q_{\mathrm{F}_{i}}$ represent the output of foreign marketing agent $i$ in the export

\footnotetext{
${ }^{5}$ As will be made clear in a moment, this distinction between the input market and final product market is motivated purely for expositional convenience.

${ }^{6}$ For a detailed discussion of US antitrust law that governs transactions in vertically structured markets, see Perloff et al. (1996).

${ }^{7}$ Because the STE acts as a cooperative, the profit maximizing transfer price is independent of the level of the lump-sum transfer; hence the size of the final transfer payment can be suppressed without loss of generality.
} 
market. Letting $n$ denote the number of foreign agents, the aggregate output of foreign firms is $q_{\mathrm{F}}=\sum_{i=1}^{n} q_{\mathrm{F}_{i}}$. For foreign marketing agent $i$, the objective function in the output stage is

$$
\pi_{\mathrm{F}_{i}}\left(q_{\mathrm{F}_{i}}, Q\right)=\left(P(Q)-c_{\mathrm{F}}\right) q_{\mathrm{F}_{i}},
$$

which yields the first-order condition

$$
P(Q)+q_{\mathrm{F}_{i}} P(Q)-c_{\mathrm{F}}=0
$$

Equilibrium in the output stage is found by simultaneously solving the $n+1$ equations described in (3) and (4).

To achieve greater analytic tractability, the remainder of the paper confines attention to the case of symmetric foreign firms, $q_{\mathrm{F}_{i}}=(1 / n) q_{\mathrm{F}}, \forall i$. In this case, the above system of equations can be simplified by aggregating the $n$ first-order conditions (4), which yields the first-order condition for a representative marketing agent

$$
P(Q)+(1 / n) q_{\mathrm{F}} P^{\prime}(Q)-c_{\mathrm{F}}=0
$$

The equilibrium export volume of the final good from domestic and foreign marketing agents, denoted $q_{i}(w, c), i=D, F$, and the total quantity sold in the export market, $Q(w, c)$, are obtained by solving (3) and (5) simultaneously.

In the precommitment stage, the STE selects the transfer price, $w$, so as to

$$
\operatorname{Max}_{w} \pi_{\mathrm{D}}(w)=(P(Q(w, c))-c) q_{\mathrm{D}}(w, c) .
$$

Letting $w^{*}$ denote the solution to this problem, the upstream price set by the STE in the optimal rent-shifting program is

$$
w^{*}-c_{\mathrm{D}}=-q_{\mathrm{D}}^{*} P^{\prime}\left(Q^{*}\right) \frac{\partial q_{\mathrm{F}}}{\partial q_{\mathrm{D}}}\left(q_{\mathrm{D}}^{*}, Q^{*}\right)<0
$$

where

$$
\frac{\partial q_{\mathrm{F}}}{\partial q_{\mathrm{D}}}\left(q_{\mathrm{D}}^{*}, Q^{*}\right)=\left(n P^{\prime}\left(Q^{*}\right)+q_{\mathrm{F}}^{*} P^{\prime \prime}\left(Q^{*}\right)\right)\left[(n+1) P^{\prime}\left(Q^{*}\right)+q_{\mathrm{F}}^{*} P^{\prime \prime}\left(Q^{*}\right)\right]^{-1}
$$

is the ratio of comparative statics of (3) and (5) implied by the STE's choice of $w$, and where the inequality in (7) holds by stability condition (1). In expression (7), the profit-maximizing upstream price set by the STE specifies that domestic upstream producers sell the input at a price below marginal cost, which increases domestic market share in the international market in an analogous fashion as a domestic output subsidy. 


\section{Empirical methodology}

In a standard empirical industrial organization model, the theoretical underpinning of the market equilibrium is a simultaneous-move game comprised of homogeneous firms (for a review, see Bresnahan (1989)). For our purposes, we extend this framework to consider an international market equilibrium composed of two exporting groups: the CWB and a composite group of symmetric foreign marketing agents that operate without the services of a STE.

Our statistical approach begins with estimation of the output stage model. For empirical purposes, we write the conjectural variations counterparts to (3) and (5) with the use of conduct parameters. ${ }^{8}$ The conjectural variations model arises by assuming each firm views industry output $Q$ as a function of it's own output $q_{i}$, which modifies (3) and (5) as

$$
\begin{aligned}
& P+q_{\mathrm{c}} P^{\prime}\left(\mathrm{d} Q / \mathrm{d} q_{\mathrm{c}}\right)-w=0, \\
& P+q_{\mathrm{oe}} P^{\prime}\left(\mathrm{d} Q / \mathrm{d} q_{\mathrm{oe}}\right)-c_{\mathrm{oe}}=0,
\end{aligned}
$$

for the CWB and the composite group of other exporters, respectively, which we hereafter denote with the subscripts $\mathrm{c}$ and oe. Noting that $\mathrm{d} Q / \mathrm{d} q_{i}=\mathrm{d} q_{i} / \mathrm{d} q_{i}+$ $\mathrm{d} q_{-i} / \mathrm{d} q_{i}$, where $-i$ refers to the combined output of all marketing agents other than $i$, and letting $m=c_{\mathrm{c}}-w$ denote the markdown payment of the CWB, the conjectural variations counterparts to (3) and (5) are

$$
\begin{aligned}
& P+q_{\mathrm{c}} P^{\prime} \lambda_{\mathrm{c}}-c_{\mathrm{c}}+m=0, \\
& P+q_{\mathrm{oe}} P^{\prime} \lambda_{\mathrm{oe}}-c_{\mathrm{oe}}=0,
\end{aligned}
$$

where $\lambda_{i}=1+v_{i}$ is a conduct parameter and the variable $v_{i} \equiv\left(\mathrm{d} q_{-i} / \mathrm{d} q_{i}\right)$, accordingly, is the so-called 'conjectural variation.' In Eqs. $\left(3^{\prime}\right)$ and $\left(5^{\prime}\right)$, the departure of $\lambda_{i}$ from unit value is a logically consistent test of whether the Cournot-Nash model provides an accurate description of the industry equilibrium. Under the rent-shifting hypothesis, the optimal markdown payment of the CWB in $\left(3^{\prime}\right)$, denoted $m^{*}$, is defined by $m^{*}=c_{\mathrm{c}}-w^{*}$ in accordance with (7).

Our approach essentially is to estimate Eqs. $\left(3^{\prime}\right)$ and $\left(5^{\prime}\right)$. However, an econometric problem arises in that rent-shifting behavior derives from a previous, precommitment period in which the optimal markdown payment, $m^{*}$, is determined through the use of output-stage information. A two-step method corrects for this problem. In the first step, the value of $m$ in $\left(3^{\prime}\right)$ is taken as the observed

\footnotetext{
${ }^{8}$ It is well understood that the conduct parameter framework has no valid dynamic foundation. However, it provides a convenient way to characterize the spectrum of oligopoly outcomes and it is commonly used in empirical industrial organization studies. Genesove and Mullin (1998) provide a good discussion of the possibilities and limitations of the conduct parameter approach.
} 
markdown payment set by the CWB, which we denote $\bar{m}$, and price and cost information is employed to estimate conduct parameters for the CWB and foreign marketing agents in the output-stage model. Because $\bar{m}$ represents the actual markdown payment instituted by the CWB in each sample year, moreover, this procedure yields unbiased estimates of the various market parameters. In the second step, the estimated output stage results are used to recover the optimal rent-shifting markdown in the precommitment stage and nonparametric statistical tests are applied to evaluate the relationship between the estimated optimal and observed markdown payments set by the CWB.

The two-step approach outlined above has several advantages. First, if the CWB employs its delayed producer payment system to obtain an optimal rent-shifting position in the international market, as we hypothesize, then we should observe a zero conjecture for the CWB in the output stage (i.e., $\nu_{c}=0$ ). Indeed, if the CWB set its initial payment level according to (7) in the precommitment period, the conjectural variation parameter is precisely the information that is subsumed into the optimal markdown payment, $m^{*}$.

To derive this result more formally, it is helpful to integrate the two stages of the CWB problem into a single marketing problem, from which we obtain the first-order condition

$$
P+q_{\mathrm{c}}\left(1+\nu_{\mathrm{c}}\right)-c_{\mathrm{c}}=0 .
$$

If the CWB does not employ delayed producer payments as a rent-shifting mechanism, so that information from the precommitment stage is ignored, the markdown payment $m$ in $\left(3^{\prime}\right)$ is a pure monetary transfer that has no real economic effect on industry competitiveness. If the CWB operates an optimal rent-shifting program, however, then from (7), unit production costs relate to the procurement price according to $c_{\mathrm{c}}=w^{*}+q_{\mathrm{c}} \nu_{\mathrm{c}}$, which implies

$$
P+q_{\mathrm{c}}\left(1+\nu_{\mathrm{c}}\right)-c_{\mathrm{c}}=P+q_{\mathrm{c}}-w^{*}=0 .
$$

Substituting in for the definition of the optimal markdown payment, $m^{*}=c_{\mathrm{c}}-w^{*}$, yields

$$
P+q_{\mathrm{c}}-c_{\mathrm{c}}+m^{*}=0
$$

which is equivalent to $\left(3^{\prime}\right)$ only when $\lambda_{\mathrm{c}}=1$.

The determinacy of the CWB 'conjecture' under rent-shifting behavior provides a testable implication in the output stage model. If CWB conduct is estimated as a free parameter in an output stage in which the marginal cost of the CWB is shifted downward by the observed markdown payment, $\bar{m}$, then, under the rent-shifting hypothesis, $\lambda_{\mathrm{c}}=1$ should obtain.

If the hypothesis of leadership behavior is not rejected in the output stage, a second testable implication derives in the precommitment stage model. In particular, based on the relationship between the observed payment set by the CWB in the upstream durum market and the estimated optimal markdown 
payment calculated from (7), it is possible to assess whether $\bar{m}$ is consistent with the profit-maximizing level of precommitment. Standard nonparametric statistical methods can then be applied to investigate the relationship between $\bar{m}$ and $m^{*}$.

To complete the specification of the empirical model, we consider international demand for durum given by the isoelastic demand equation, $P=\alpha Q^{1 / \varepsilon}$, where $\varepsilon<0$ is the price elasticity of demand. Substituting $\left(3^{\prime}\right)$ and $\left(5^{\prime}\right)$ in the calculation of (7) and making use of the fact that $Q P^{\prime} / P=1 / \varepsilon$ and $Q P^{\prime \prime} / P^{\prime}=(1-\varepsilon) / \varepsilon$, the optimal markdown, $m^{*}$, is characterized by

$$
m^{*}=c_{\mathrm{c}}-w^{*}=\left(\frac{-S_{\mathrm{c}}^{*} P}{\varepsilon}\right)\left(\frac{\varepsilon+\lambda_{\mathrm{oe}} S_{\mathrm{oe}}^{*}(1-\varepsilon)}{\left(1+\lambda_{\mathrm{oe}}\right) \varepsilon+\lambda_{\mathrm{oe}} S_{\mathrm{oe}}^{*}(1-\varepsilon)}\right)
$$

where $S_{\mathrm{c}}^{*}$ is the export market share of the CWB and $S_{\mathrm{oe}}^{*}=\sum_{i=1}^{n}\left(q_{\mathrm{oe}, i} / Q\right)$ is the combined market share of other exporters. For given estimated values of the demand elasticity and the conduct parameter of the other exporters $\lambda_{\mathrm{oe}}$ in the output stage of the model, expression (8) generates the estimated optimal markdown payment for each marketing year.

\section{Estimation and results}

Our analysis begins with the estimation of the output stage model. In the output stage, we consider a three-region trade model in which the CWB and the aggregate US-EU other exporter region constitute two distinct net export regions and the rest of the world (ROW) are treated as net importers. All equations are expressed in log linear form, which corrects for the perfect collinearity problem of the linear Bresnahan model (see Perloff and Shen, 1999) and is consistent with our specification of the demand relation (8). We describe the demand and supply equations for the importing region (i.e., ROW) as follows:

$$
\begin{aligned}
& D_{\text {row }}=a_{0}+a_{1} P_{\mathrm{d}}+a_{3} Y_{\text {row }}+a_{3} P_{\mathrm{r}}+a_{4}\left(P_{\mathrm{d}}^{*} P_{\mathrm{r}}\right)+\varepsilon_{a} \\
& S_{\text {row }}=b_{0}+b_{1} P_{\mathrm{d}[-1]}+b_{2} A C_{\text {row }[-1]}+b_{3} P_{\mathrm{b}[-1]}+\varepsilon_{b}
\end{aligned}
$$

where $S_{\text {row }}$ and $D_{\text {row }}$ are production and consumption of durum in the ROW region, respectively, $P_{\mathrm{d}}$ is the international price of durum, $Y_{\text {row }}$ is national income in the ROW region, $P_{\mathrm{r}}$ is the price of a key a substitute product (rice), $A C_{\text {row }}$ is durum acreage planted, and $P_{\mathrm{b}}$ is the price of a production substitute (barley), and $\varepsilon_{a}$ and $\varepsilon_{b}$ are random disturbance terms. The [-1] subscripts refer to variables lagged one period, which reflects the fact that durum supply decisions in a given year are determined prior to the marketing period, and hence depend on lagged 
values of prices and acreage. The excess demand relation for the ROW is characterized by $E D_{\text {row }} \equiv D_{\text {row }}-S_{\text {row }}$, which, making use of (9) and (10), we express in price-dependent form as:

$$
\begin{aligned}
& P_{\mathrm{d}}\left(\frac{1}{a_{1}+a_{4} P_{\mathrm{r}}}\right)\left(E D_{\text {row }}-a_{0}+b_{0}+b_{1} P_{\mathrm{d}[-1]}-a_{2} Y_{\text {row }}-a_{3} P_{\mathrm{r}}\right. \\
& \left.+b_{2} A C_{\text {row }[-1]}+b_{3} P_{b[-1]}\right)+\varepsilon_{a b}
\end{aligned}
$$

Suppose the two net export regions, Canada and OE, select quantities so as to equate perceived marginal revenue with marginal cost in $\left(3^{\prime}\right)$ and $\left(5^{\prime}\right)$. Confining attention to such cases allows for simultaneous identification of the supply relationship and conduct parameter based on exogenous rotations of the excess demand curve through the interaction term $P_{\mathrm{d}}^{*} P_{\mathrm{r}}$ in (9). Moreover, because the supply relation (10) does not depend on current year price information, the estimated demand elasticity in the ROW region is identical to that of imported durum.

For the OE region, net exports are specified in a similar fashion as above. However, an important distinction is that we consider stocks holding activities in the excess supply relation. The supply, demand and stocks equations for the $\mathrm{OE}$ region are specified as

$$
\begin{aligned}
& D_{\mathrm{oe}}=c_{0}+c_{1} P_{\mathrm{d}}+c_{3} Y_{\mathrm{oe}}+a_{3} P_{\mathrm{r}}+a_{4}\left(P_{\mathrm{d}}^{*} P_{\mathrm{r}}\right)+\varepsilon_{\mathrm{c}} \\
& S_{\mathrm{oe}}=d_{0}+d_{1} P_{\mathrm{d}[-1]}+d_{2} A C_{\mathrm{oe}[-1]}+d_{3} P_{\mathrm{b}[-1]}+d_{4} B S T_{\mathrm{oe}}+\varepsilon_{\mathrm{d}} \\
& E S T_{\mathrm{oe}}=e_{0}+e_{1} P_{\mathrm{d}}+e_{2} B S T_{\mathrm{oe}}+\varepsilon_{e}
\end{aligned}
$$

where $B S T_{\mathrm{oe}}$ and $E S T_{\mathrm{oe}}$ denote beginning and ending stocks, respectively, and all other variables are defined as in the case of the ROW above. In (14), ending stocks are modeled as a function of beginning stocks and the contemporaneous price of durum. Making use of (12)-(14), the following identity is used to calculate excess supply in the OE region $\left(E S_{\mathrm{oe}}\right)$ :

$$
S_{\mathrm{oe}}+B S T_{\mathrm{oe}} \equiv D_{\mathrm{oe}}+E S T_{\mathrm{oe}}+E S_{\mathrm{oe}}
$$

The excess supply equation also includes a shift term that captures the equilibrium deviation of price from marginal cost represented in $\left(5^{\prime}\right)$, which implies, upon gathering equations, that

\footnotetext{
${ }^{9}$ The use of lagged acreage is conceptually similar to the use of a lagged supply term but, by removing weather related output factors, better captures the previous period's production commitment.
} 


$$
\begin{aligned}
P_{\mathrm{d}}= & \left(\frac{-1}{c_{1}+c_{4} P_{\mathrm{r}}+e_{1}}\right)\left(E S_{\mathrm{oe}}+c_{0}-d_{0}+e_{o}-d_{1} P_{\mathrm{d}[-1]}-d_{2} A C_{\mathrm{oe}[-1]}-d_{3} P_{\mathrm{b}}\right. \\
& \left.+\left(1+c_{4}-e_{2}\right) B S T_{\mathrm{oe}}+c_{2} Y_{\mathrm{oe}}+c_{3} P_{\mathrm{r}}\right) \\
& -\lambda_{\mathrm{oe}} E S_{\mathrm{oe}}\left(\frac{1}{a_{1}+P_{\mathrm{r}} a_{4}}\right)+\varepsilon_{\mathrm{cd}}
\end{aligned}
$$

where $\lambda_{\mathrm{oe}}$ is the conduct parameter for the $\mathrm{OE}, \varepsilon_{\mathrm{cd}}$ is a random disturbance term, and all other variables are as previously defined.

For the Canadian region, the supply, demand, stocks and excess supply equations are analogous to those of the OE region in (12)-(16), with one exception. The marginal cost facing the wheat board in the output stage is reduced by the observed markdown payment, $\bar{m}$, as specified by $\left(3^{\prime}\right)$. Proceeding as above yields the estimation equations

$$
\begin{aligned}
& D_{\mathrm{c}}=f_{0}+f_{1} P_{\mathrm{d}}+f_{3} Y_{\mathrm{c}}+f_{3} P_{\mathrm{r}}+f_{4}\left(P_{\mathrm{d}}^{*} P_{\mathrm{r}}\right)+\varepsilon_{f} \\
& S_{\mathrm{c}}=g_{0}+g_{1} P_{\mathrm{d}[-1]}+g_{2} A C_{\mathrm{c}[-1]}+g_{3} P_{\mathrm{b}[-1]}+g_{4} B S T_{\mathrm{c}}+\varepsilon_{g} \\
& E S T_{\mathrm{c}}=h_{0}+{ }_{1} P_{\mathrm{d}}+h_{2} B S T_{\mathrm{c}}+\varepsilon_{h} \\
& P_{\mathrm{d}}+\bar{m} \\
& =\left(\frac{-1}{f_{1}+f_{4} P_{\mathrm{r}}+h_{1}}\right)\left(E S_{\mathrm{c}}+f_{0}-g_{0}+h_{o}-g_{1} P_{\mathrm{d}[-1]}-g_{2} A C_{\mathrm{c}[-1]}-g_{3} P_{\mathrm{b}}\right. \\
& \left.\quad+\left(1+g_{4}-h_{2}\right) B S T_{\mathrm{c}}+f_{2} Y_{\mathrm{c}}+f_{3} P_{\mathrm{r}}\right) \\
& \quad-\lambda_{\mathrm{c}} E S_{\mathrm{c}}\left(\frac{1}{a_{1}+a_{4} P_{\mathrm{r}}}\right)+\varepsilon_{f g} .
\end{aligned}
$$

The data necessary to estimate the model are acquired as follows. International prices, acreage, consumption, production, trade, beginning and ending stocks for the various hard wheat commodities are obtained from World Wheat Statistics. Per capita income for each region is calculated using GDP data reported in International Financial Statistics and population data in the United Nations Population Database. Finally, the (real) international prices of barley and rice are obtained from North American export values available in the United Nations Trade Database and deflated using the industrialized nations producer price index reported in International Financial Statistics.

The system of equations above is estimated for the durum market over the pre-WTO period 1971-1995..$^{10}$ Since Eqs. (9)-(20) represent a nonlinear simulta-

\footnotetext{
${ }^{10}$ In light of the fact that the US began investigating the trade implications of STE behavior in 1995 (see GAO $(1995,1996)$ ), we confine attention to prior years.
} 
neous equation system, they are estimated using nonlinear three-stage least squares (N3SLS). The exogenous variables in the system are used as instruments and convergence is obtained from various groups of starting values.

The estimation results are presented in Table 1. The important feature to note in the table is that each parameter estimate essential to our test of the rent-shifting hypothesis is of the correct sign and of a magnitude that conforms either with theory or to previous research. In particular, the coefficients that jointly determine the world demand elasticity in the ROW region, $a_{1}$ and $a_{4}$, are both significant. Based on these values, the estimated demand elasticity in the durum export market (evaluated at the mean price of rice) is -2.1612 and is significant at the 0.01 level. Using the observed price of rice at each data point, the elasticity of international durum demand varies in a range between -2.50 to -1.50 over the sample period. ${ }^{11}$ The ROW cross-price elasticity with rice, estimated at the mean durum price, is positive, which conforms to expectations that rice and durum are substitutes in consumption. Income parameters for Canada and the OE indicate that durum is a normal good.

Most of the remaining parameters from the supply equations and stocks equations either conform to expectations or are not statistically significant. The price of barley, which is included in the model as a production substitute for durum, is statistically significant in all three regions, but of the wrong sign in the ROW region. This finding may be due to the fact that barley is a substitute in Canadian and $\mathrm{OE}$ growing regions, but less important to the diverse growing regions characterized by the ROW. The parameters for beginning stocks in the ending stocks equations are positive and statistically significant in both export regions, with magnitudes that indicate more pronounced stocks adjustments in the US than in Canada. In each case, stocks holding behavior is positively related to the world export price, which indicates that both regions may attempt to influence the world market price for durum through grain storage.

The conduct parameters, both for the CWB $\left(\lambda_{\mathrm{c}}=1.05\right)$ and for the OE region $\left(\lambda_{\mathrm{oe}}=0.74\right)$, are statistically significant, which provides some indication that the world durum market is noncompetitive. Making use of the output stage estimation results, moreover, the hypothesis that $\lambda_{\mathrm{c}}=1$ cannot be rejected. ${ }^{12}$ Hence, we fail to reject the hypothesis in the output stage model that the CWB shifts rent through its delayed producer payment program.

The estimated conduct of the CWB in the output stage provides a necessary, but

\footnotetext{
${ }^{11}$ To our knowledge, there is no published research that reports estimates of the import demand elasticity for durum over a comparable period of study. However, empirical evidence in hard wheat and course grain markets suggests that the import demand elasticities reported here are quite reasonable (see, e.g., Paarlberg and Abbott (1986), Tyers and Anderson (1988), and Devadoss and Meyers (1990)).

${ }^{12}$ In contrast, a similar test on the conduct parameter for the OE region rejects the hypothesis of unit value at the 0.05 level.
} 
Table 1

Model estimates for Durum Export Demand 1971-1995

\begin{tabular}{|c|c|c|c|}
\hline Description & Parameter & Coefficient & $t$-ratio \\
\hline \multicolumn{4}{|l|}{$R O W$ (net import) region } \\
\hline Demand intercept & $a_{0}$ & $14.6 *$ & 3.54 \\
\hline Durum price & $a_{1}$ & $-5.53 *$ & -4.34 \\
\hline ROW income & $a_{2}$ & $-1.41 *$ & -5.17 \\
\hline Rice price & $a_{3}$ & -0.97 & -0.99 \\
\hline Rice*durum interaction & $a_{4}$ & $0.82 *$ & 2.78 \\
\hline Supply intercept & $b_{0}$ & $4.24 *$ & 7.26 \\
\hline Lagged durum price & $b_{1}$ & -0.01 & -0.25 \\
\hline Lagged acreage & $b_{2}$ & $-1.04 *$ & -3.64 \\
\hline Lagged price of barley & $b_{3}$ & $0.33^{*}$ & 5.13 \\
\hline \multicolumn{4}{|l|}{$O E$ (net export) region } \\
\hline Demand intercept & $c_{0}$ & $-21.20^{*}$ & -2.73 \\
\hline Durum price & $c_{1}$ & 4.07 & 1.99 \\
\hline OE income & $c_{2}$ & $5.12 *$ & 5.54 \\
\hline Rice Price & $c_{3}$ & -0.26 & -0.17 \\
\hline Rice*durum interaction & $c_{4}$ & -0.49 & -1.07 \\
\hline Supply intercept & $d_{0}$ & $3.06^{*}$ & 9.04 \\
\hline Lagged durum price & $d_{1}$ & 0.11 & 1.45 \\
\hline Lagged acreage & $d_{2}$ & -0.28 & -1.64 \\
\hline Lagged price of barley & $d_{3}$ & $-0.35^{*}$ & -4.18 \\
\hline Beginning stocks & $d_{4}$ & 0.16 & 1.64 \\
\hline Stocks intercept & $e_{0}$ & $-1.46^{*}$ & -2.85 \\
\hline Durum price & $e_{1}$ & $0.49 *$ & 3.70 \\
\hline Beginning stocks & $e_{2}$ & $0.82 *$ & 5.40 \\
\hline \multicolumn{4}{|l|}{ Canada (net export) region } \\
\hline Demand intercept & $f_{0}$ & -8.61 & -1.90 \\
\hline Durum price & $f_{1}$ & 1.66 & 1.44 \\
\hline Canada income & $f_{2}$ & $2.06^{*}$ & 4.19 \\
\hline Rice price & $f_{3}$ & -0.37 & -1.02 \\
\hline Rice*durum interaction & $f_{4}$ & -0.20 & -1.13 \\
\hline Supply intercept & $g_{0}$ & $1.91 *$ & 6.02 \\
\hline Lagged durum price & $g_{1}$ & -0.02 & -0.17 \\
\hline Lagged acreage & $g_{2}$ & 0.12 & 1.16 \\
\hline Lagged price of barley & $g_{3}$ & $-0.32 *$ & -2.62 \\
\hline Beginning stocks & $g_{4}$ & $-0.46^{*}$ & -9.21 \\
\hline Stocks intercept & $h_{0}$ & $-1.18^{*}$ & -3.53 \\
\hline Durum price & $h_{1}$ & $0.46^{*}$ & 4.63 \\
\hline Beginning stocks & $h_{2}$ & $0.28^{*}$ & 4.06 \\
\hline \multicolumn{4}{|l|}{ Conduct parameters } \\
\hline Canada conduct & $\lambda_{\mathrm{c}}$ & $1.058^{*}$ & 4.41 \\
\hline OE conduct & $\lambda_{\mathrm{oe}}$ & $0.742 *$ & 9.46 \\
\hline
\end{tabular}

\footnotetext{
*Statistically significant at the 0.05 level.
} 
not a sufficient, condition for rent-shifting behavior. ${ }^{13}$ Consequently, we next turn to the question of whether the observed CWB markdown payments are consistent with the optimal employment of a rent-shifting mechanism in the precommitment stage.

Fig. 2 compares (in percentage terms) the observed markdown in the durum market, $\bar{m}$, with the estimated optimal markdown payment over the 1972-95 period, $m^{*}$. The observed markdown payment in each period is taken to be the difference between the initial procurement price and the global market price for durum, while the estimated optimal markdown is based on the relevant output stage coefficients that comprise Eq. (8). Other than notable exceptions that occur in the years 1980, 1987, 1990, and 1995, the estimated optimal markdown price seems to track fairly closely with the observed markdown payments implemented by the CWB. This provides some casual evidence that the markdown payments set by the CWB are set at the optimal level to shift rent.

Before proceeding with a more formal analysis of the precommitment stage, we first assess the extent to which the correspondence between $\bar{m}$ and $m^{*}$ provides evidence to support the optimality of payments in a rent-shifting program. It is important to note that the calculation of the optimal markdown payment in (8) relies on the use of estimated coefficients in the output stage model $\left(a_{1}, a_{4}\right.$ and $\left.\lambda_{\mathrm{oe}}\right)$, where each of these parameters, in turn, is conditional on the vector of observed markdown payments, $\bar{m}$. For this reason, it is necessary to address the

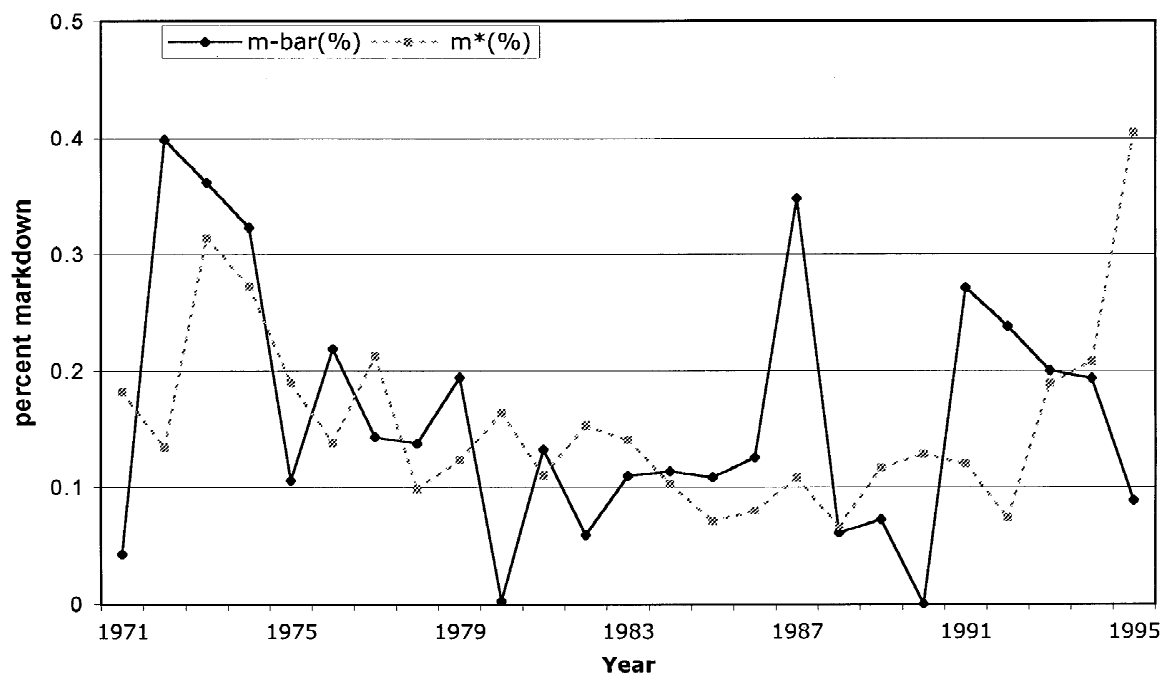

Fig. 2. Percentage comparison of the estimated optimal and actual markdown, 1971-95.

\footnotetext{
${ }^{13}$ Indeed, a unit conduct parameter is also consistent with static, 'one-shot' Cournot-Nash competition.
} 
extent to which $m^{*}$ is conditioned by $\bar{m}$ through the output stage coefficients before inferences are drawn regarding the optimality of the observed markdown payments.

To evaluate this issue, we calculate the sensitivity of $m^{*}$ to various perturbations in $\bar{m}$. In particular, we re-estimate the output stage model following several percentage magnitude adjustments in $\bar{m}$. The conduct parameter and coefficients that determine the demand elasticity are extremely robust in response to each of these perturbations. For the largest magnitude change, a $20 \%$ increase in $\bar{m}$, the parameters relevant to our calculation of $m^{*}, a_{1}, a_{4}$ and $\lambda_{\text {oe }}$, decrease in absolute value terms by $1.38,1.66$ and $0.01 \%$, respectively. The arc elasticity of $m^{*}$ with respect to $\bar{m}$ is 0.041 for each magnitude of the change, with a range that varies between 0.029 and 0.054 across individual data points (due to variation in output levels). These results indicate that the calculated value of $m^{*}$ is not highly conditional on $\bar{m}$ in our sample. . $^{14}$

The observed and estimated optimal markdown payments are reported in Table 2 . The difference between the values of $\bar{m}$ and $m^{*}$ in each sample year provides the basis for our statistical assessment of the rent-shifting hypothesis in the precommitment stage. On average, the observed markdown payment set by the CWB is $\$ 26.03$, whereas the estimated optimal markdown is $\$ 24.14$ in the sample period. Because we have limited knowledge of the underlying distributional properties of $m^{*}$, we apply two nonparametric techniques to evaluate the hypothesis that $\bar{m}=m^{*}$. The first technique employs a standard nonparametric bootstrap procedure on the system of equations to generate a confidence interval about $m^{*}$, which allows the hypothesis of equal markdown payments to be examined in each sample year. ${ }^{15}$ The bootstrap is implemented by generating OLS parameter estimates of the reduced form system and sampling (with replacement) from the errors of the reduced form equations to create 1000 simulated pseudosamples of the endogenous variables. The simulated endogenous variables are then introduced into the structural system to generate the vector of structural parameter estimates necessary to calculate $m^{*}$ in each sample year.

For each marketing year, the third column of Table 2 reports the bootstrap $P$ value for a test of equal coefficients, $\bar{m}=m^{*}$. In 1980 and 1990, the observed

\footnotetext{
${ }^{14}$ An anonymous referee suggested an alternative way to address this issue. To the extent that an estimated optimal markdown payment is conditional on the observed markdown payment, suboptimal behavior may appear to be optimal in the precommitment stage comparison (type II error). To evaluate this possibility, we uniformly increase each observed markdown payment by $\$ 5$ (a mean increase of $19.2 \%$ ) and re-estimate the output-stage model. The calculated values of the optimal markdown payments differ only marginally from those reported in Table 2 and, correspondingly, the hypothesis that the suboptimal payment level are optimal is rejected on the basis of the Wilcoxen signed-rank test (described in detail below).

${ }^{15}$ See Efron and Tibshirani (1993) for a general discussion of this approach.
} 
Table 2

Estimated optimal versus observed markdowns by the CWB in the international durum market 1972-1995

\begin{tabular}{|c|c|c|c|}
\hline Year & $\begin{array}{l}\bar{m} \\
\text { Observed } \\
\text { markdown }\end{array}$ & $\begin{array}{l}m^{*} \\
\text { Estimated } \\
\text { optimal } \\
\text { markdown }\end{array}$ & $\begin{array}{l}\text { Bootstrap } \\
P \text { value } \\
\text { (two-sided } \\
\text { alternative) }\end{array}$ \\
\hline 1972 & 42.08 & 14.18 & $0.0001^{*}$ \\
\hline 1973 & 88.22 & 76.58 & 0.8572 \\
\hline 1974 & 74.55 & 62.82 & 0.6818 \\
\hline 1975 & 18.00 & 32.29 & 0.1268 \\
\hline 1976 & 30.22 & 19.02 & 0.0901 \\
\hline 1977 & 16.54 & 24.60 & 0.2076 \\
\hline 1978 & 17.07 & 12.19 & 0.3078 \\
\hline 1979 & 33.82 & 21.47 & 0.1188 \\
\hline 1980 & 0.49 & 32.43 & $0.0150^{*}$ \\
\hline 1981 & 21.79 & 18.11 & 0.4654 \\
\hline 1982 & 8.74 & 22.74 & 0.1188 \\
\hline 1983 & 17.54 & 22.46 & 0.7040 \\
\hline 1984 & 17.13 & 15.54 & 0.5028 \\
\hline 1985 & 13.66 & 8.97 & 0.1106 \\
\hline 1986 & 13.18 & 8.36 & 0.1142 \\
\hline 1987 & 44.02 & 13.65 & $0.0000^{*}$ \\
\hline 1988 & 10.11 & 10.99 & 0.6100 \\
\hline 1989 & 9.91 & 15.94 & 0.6744 \\
\hline 1990 & 0.00 & 13.48 & $0.0434^{*}$ \\
\hline 1991 & 30.61 & 13.51 & $0.0006^{*}$ \\
\hline 1992 & 28.80 & 8.88 & $0.0001^{*}$ \\
\hline 1993 & 34.27 & 32.44 & 0.6064 \\
\hline 1994 & 36.04 & 38.74 & 0.9920 \\
\hline 1995 & 17.98 & 82.29 & $0.0006^{*}$ \\
\hline
\end{tabular}

\footnotetext{
${ }^{\ddagger}$ Values of $\bar{m}$ and $m^{*}$ statistically dissimilar at the 0.05 level; Wilcoxen test statistic: $Z$ score, $-0.713 ; P$ value, 0.4778 .
}

markdown payment implemented by the CWB is either zero or near zero, which indicates that a rent-shifting markdown payment was not implemented. Of the remaining sample years in which a positive markdown is observed, the results fail to reject the hypothesis of equal coefficients at the 0.05 level in 17 of 22 cases. Thus, in the majority of years in the sample the markdown payment instituted by the CWB is not statistically different from the optimal rent-shifting markdown at the bootstrapped sample means. In four of the five remaining years in which the hypothesis of equal coefficient is rejected, the observed markdown set by the CWB exceeded the level necessary to acquire the optimal rent-shifting advantage in the durum market. Each of these cases corresponds with a strong leadership signal, although an excessive markdown payment is clearly sub-optimal in context of the 
static theoretical structure that frames our approach. Only in 1995, the final sample year in our study, is the observed markdown payment both significantly different than zero and below the estimated optimal markdown. ${ }^{16}$

We next examine the correspondence between the estimated and observed markdown payments in the entire sample range. The overall agreement between $\bar{m}$ and $m^{*}$ in the entire 1972-95 sample range is central to our analysis of the precommitment stage, particularly when one considers that the final world price is to some extent uncertain at the time the initial payment is announced. ${ }^{17}$ In any given year, exogenous shocks (e.g., output shocks due to weather events) can potentially occur between the time the initial and final payments are made that influence the performance of the rent-shifting policy. Provided that the exogenous shocks are uncorrelated, however, extending the analysis to the entire sample range dampens the influence of such events, even in a small time series such as ours.

To address the general relationship between the observed and estimated optimal markdown payments over the sample period, we employ a Wilcoxen signed-rank test (see Wilcox (1987)). The Wilcoxen test, which relies on sequentially ranked differences of the median values of $\bar{m}$ and $m *$ is used to generate a $Z$ score for the hypothesis that $\bar{m}=m^{*}{ }^{18}$ The result of this test is reported with its corresponding $P$ value at the bottom of Table 2. With 24 pairs of observations of the ranked data, we fail to reject the hypothesis that the estimated optimal and observed markdown payments coincide over the sample period. Thus, the results of the Wilcoxen signed-rank test suggest that the procurement pricing structure of the CWB in the precommitment stage is indeed consistent with the rent-shifting hypothesis. ${ }^{19}$

Several features may explain why our sample involves a higher observed markdown on average than the estimated optimal markdown payment. First, the delayed producer payment system may provide ancillary benefits not considered in our analysis, such as a source of interest-free short-term loans to manage day-to-day operations of the CWB. Second, the CWB controls both the transfer price and the quantity marketed for export, which allows greater latitude for strategic behavior than that which is considered here. Finally, our estimates of the

\footnotetext{
${ }^{16}$ Although we do not wish to press the point here, it is interesting to note that the 1995 marketing year also corresponds to the first year of the US Congressional investigation into STE behavior (GAO, 1995, 1996).

${ }^{17}$ To obtain unbiased parameter estimates in the output stage model, however, it is necessary to consider the markdown payment as the observed deviation from the actual market price, not the expected market price.

${ }^{18}$ If each difference is from some symmetric distribution, of course, then any inference about the median also applies to the mean.

${ }^{19}$ We also performed two other tests on the relationship of and $m^{*}$ : a simple $t$-test of the means and Spearman's coefficient of rank correlation, neither of which differed significantly from the Wilcoxen test results.
} 
output stage parameters are based on information from the entire sample period, whereas the CWB operates on a year-by-year marketing basis. On the whole, while one should be alert to the possibility of data problems, our findings seem remarkably consistent with the hypothesis that the delayed payment system of the CWB serves as a rent-shifting mechanism in the international durum market.

\section{Concluding remarks}

The purpose of this paper was to derive and implement a general test of rent-shifting behavior in international markets. Our examination of the international durum market, in which the CWB acts as the sole exporter for Canada, failed to reject the hypothesis that the pricing structure employed by the CWB is targeted at the optimal level to shift rent.

The empirical approach we developed here to test the rent-shifting hypothesis provides a general methodology for the examination of multi-stage games in non-competitive markets. The empirical analysis was conducted using two procedures that correspond, in parallel fashion, with each of the two stages of the theory. In the first procedure, the output stage of the model was estimated using conduct parameters to describe equilibrium market behavior in an environment that considered the strategic manipulation of a policy parameter in the domestic marginal cost relation. A testable implication resulted for these output stage estimation results. Namely, it was demonstrated that a necessary, though not a sufficient, condition for rent-shifting behavior is a unit value for the estimated conduct parameter of the domestic marketing agent. Applied to the role of the CWB in the international durum market, this hypothesis could not be rejected. The second procedure relied on information from the precommitment stage that permits several nonparametric statistical tests to be employed to evaluate the hypothesis that the observed markdown is consistent with the optimal rent-shifting markdown. Based on these tests, the hypothesis that the delayed producer payment system of the CWB is consistent with the optimal rent-shifting policy in the 1972-95 sample period could not be rejected.

As the trend continues towards greater integration of international markets, extension of these findings to other markets (and other trade policy parameters) is essential. Evidence of similar rent-shifting policies in other export markets, whether instituted by governments through delayed producer payments and export subsidization programs or by private market mechanisms such as union-management contracts, upstream equity-sharing relations, and strategic delegation, would provide further validation for the results reported here. Such corroborative evidence is important as international free-trade agreements continue to be restructured along the lines suggested by theory. 


\section{Acknowledgements}

Senior authorship is not assigned. We thank Alan Kerr, Jeff Perloff, Ian Sheldon, and an anonymous referee for helpful comments and discussions.

\section{References}

Aw, G.Y., 1992. An empirical model of markups in a quantity-differentiated export market. Journal of International Economics 33, 327-344.

Bagwell, K., Staiger, R.W., 1994. The sensitivity of strategic and corrective R\&D policy in oligopolistic industries. Journal of International Economics 36, 133-150.

Berg, S.A., Kim, M., 1998. Banks as multioutput oligopolies: an empirical evaluation of the retail and corporate banking markets. Journal of Money, Credit and Banking 30, 135-153.

Brainard, S.L., Martimort, D., 1998. Strategic trade policy design with asymmetric information and public contracts. Review of Economic Studies 65, 627-630.

Bonanno, G., Vickers, J.S., 1988. Vertical separation. Journal of Industrial Economics 36, 257-265.

Brander, J.A., Spencer, B.J., 1984. Trade warfare: tariffs and cartels. Journal of International Economics 16, 227-242.

Brander, J.A., Spencer, B.J., 1985. Export subsidies and international market share rivalry. Journal of International Economics 18, 83-100.

Brander, J.A., Spencer, B.J., 1988. Unionized oligopoly and international trade policy. Journal of International Economics 24, 217-234.

Bresnahan, T.F., 1989. Empirical studies of industries with market power. In: Schmalensee, R., Willig, R. (Eds.). Handbook of Industrial Organization, Vol. 2. North-Holland, Amsterdam, pp. 1011-1057.

Coughlin, A.T., Wernerfelt, B., 1989. On credible delegation by oligopolists: a discussion of distribution channel management. Management Science 35, 226-239.

Devadoss, S., Meyers, W., 1990. Variability in wheat export demand elasticity: Policy implications. Agricultural Economics 4, 381-394.

Dixit, A., 1988. Anti-dumping and countervailing duties under oligopoly. European Economic Review 32, 55-68.

Efron, B., Tibshirani, R.J., 1993. In: An Introduction to the Bootstrap. Chapman and Hall, New York.

Fung, K.C., 1995. Rent shifting and rent sharing: a reexamination of the strategic industry problem. Canadian Journal of Economics 28, 450-462.

General Accounting Office, 1995, State trading enterprises: Compliance with the general agreement on tariffs and trade. Report to Congressional Requesters, GAO/GGD-95-208.

General Accounting Office, 1996, Canada, Australia, and New Zealand: Potential ability of agricultural State Trading Enterprises to distort trade, GAO/NSIAD-96-94.

Genesove, D., Mullin, W.P., 1998. Testing static oligopoly models: Conduct and cost in the sugar industry, 1890-1914. RAND Journal of Economics 29, 355-377.

Goldberg, P.K., 1995. Strategic export promotion in the absence of government precommitment. International Economic Review 36, 407-426.

Goldberg, P.K., Knetter, M.M., 1999. Measuring the intensity of competition in export markets. Journal of International Economics 47, 27-60.

Hamilton, S.F., Stiegert, K., 2000. Vertical coordination, antitrust law, and international trade. Journal of Law and Economics 43, 143-156.

Harrison, A., 1994. Productivity, imperfect competition and trade reform: theory and evidence. Journal of International Economics 36, 53-73.

International Wheat Council, World grain statistics (London), various issues. 
Ishikawa, J., Lee, K., 1997. Backfiring tariffs in vertically related markets. Journal of International Economics 42, 395-423.

Ishikawa, J., Spencer, B.J., 1999. Rent-shifting export subsidies with an imported intermediate product. Journal of International Economics 48, 199-232.

Kahai, S.K., Kaserman, D.L., Mayo, J.W., 1996. Is the 'dominant firm' dominant? An empirical analysis of AT\&T's market power. Journal of Law and Economics 39, 499-517.

Karp, L.S., Perloff, J.M., 1995. Why industrial policies fail: Limited commitment. International Economic Review 36, 887-905.

Kühn, K., 1997. Nonlinear pricing in vertically related duopolies. RAND Journal of Economics 28, 37-62.

Levinsohn, J., 1993. Testing the imports as market discipline hypothesis. Journal of International Economics 35, 1-22.

Lin, Y.J., 1988. Oligopoly and vertical integration: note. American Economic Review 78, 251-254.

Maggi, G., 1996. Strategic trade policies with endogenous mode of competition. American Economic Review 86, 237-258.

Neary, J.P., 1994. Cost asymmetries in international subsidy games: Should governments help winners or losers? Journal of International Economics 37, 197-218.

Novshek, W., 1985. On the existence of Cournot equilibrium. Review of Economic Studies 52, 85-98.

Perloff, J., Rubinfeld, D., Ruud, P., 1996. Antitrust settlements and trial outcomes. Review of Economics and Statistics 78, 401-409.

Paarlberg, P., Abbott, P., 1986. Oligopolistic behaviour by public agencies in international trade: The world wheat market. American Journal of Agricultural Economics 68, 528-542.

Perloff, J., Shen, E., 1999. Collinearity in linear structural models of market power, University of California at Berkeley Working Paper.

Qiu, L.D., 1995. Why can't countervailing duties deter export subsidization? Journal of International Economics 39, 249-272.

Spencer, B.J., Jones, R.W., 1991. Vertical foreclosure and international trade policy. Review of Economic Studies 58, 153-170.

Spencer, B.J., Jones, R.W., 1992. Trade and protection in vertically related markets. Journal of International Economics 32, 31-55.

Tyers, R., Anderson, K., 1988. Imperfect price transmission and implied trade elasticities in a multi-commodity world. In: Carter, C.A., Gardiner, W.H. (Eds.), Elasticities in International Agricultural Trade. Westview Press, London, pp. 225-295

United Nations. International Financial Statistics (New York), various issues.

United Nations. United Nations population internet database.

United Nations. United Nations trade internet database.

Wilcox, R.R., 1987. In: New Statistical Procedures for the Social Sciences: Modern Solutions to Basic Problems. Lawrence Erlbaum Associates, Hillsdale, NJ. 